\title{
COMPARISON OF GROUND-BASED AND SATELLITE DATA ON SPATIOTEMPORAL DISTRIBUTION OF LIGHTNING DISCHARGES UNDER SOLAR MINIMUM
}

\author{
V.V. Denisenko \\ Institute of Computational Modelling RAS SB, \\ Krasnoyarsk, Russia,denisen@icm.krasn.ru
}

\author{
A.N. Lyakhov \\ Sadovsky Institute of Geosphere Dynamics RAS, \\ Moscow, Russia,alyakhov@idg.chph.ras.ru
}

Worldwide maps of lightning activity have been obtained from the ground-based World Wide Lightning Location Network (WWLLN) for 2007-2009. We have compiled these maps separately for different seasons and UT periods, using WWLLN data on the time and coordinates of each of the recorded lightning. The total number of flashes of lightning in WWLLN data is by an order of magnitude smaller than in satellite data from Optical Transient Detector and the Lightning Imaging Sensor satellites. However, the key features of the spatial distribution and seasonal trends coincide well. The main difference observed is the absence of diurnal variation (similar to Carnegie curve) in WWLLN data against the satellite one. This concerns the global lightning number as well as its density in major thunderstorm regions. The solar local time dependence is also weak in WWLLN data. We show that in 20072009 the mean latitude of lightning observation is shifted to the summer hemisphere up to 10 degrees from the annual mean value. From the beginning of 2007 to the end of 2009, the global monthly average number of flashes of lightning increased threefold. We attribute this fact primarily to improved processing techniques in WWLLN. The constructed maps are necessary for numerical simulation of the Global Electric Circuit.

Keywords: atmosphere, thunderstorm activity, global distribution, seasonal dependence, daily variation.

\section{INTRODUCTION}

The last decade shows an increasing interest in the problem of the Global Electric Circuit (GEC). From our point of view, the main reason for this interest is that the GEC has unique properties, which couple various geospheres and physical processes with a wide range of spatio-temporal scales. Global climate change is linked to thunderstorm activity [Williams, 2005] via a change in the number of mesoscale convective systems, which, in turn, are responsible for the highest level of lightning activity. Moreover, the GEC may be a kernel of the physical mechanism responsible for the coupling between solar activity and meteorological and climate processes [Rycroft et al., 2000; Tinsely, 2000].

The aforementioned hypothesized physical mechanisms and their impact on the global processes in the atmosphere require robust verification. The usage of correlation analysis will never be free from the problem of hidden parameters, the sufficiency of the evidence, and the fundamental problem of hypothesizing and verifying with the same data [Von Storch and Navarra, 1999]. Thus, we need numerical models of the GEC to verify quantitatively the contribution of different physical processes.

Any GEC numerical model requires an empirical spatio-temporal distribution of lightning discharges over Earth as an input data stream. This primary model is converted further to the total electric conductive current in the atmosphere under some physical assumptions. It is worthwhile to note that spatio-temporal variations in the displacement current are neglected at the contemporary level of knowledge, though they can be significant under pulse disturbances of permittivity of the medium.

For the analysis, we have chosen the freely available database WWLLN (World Wide Lightning Location Network, https://wwlln.net). It contains coordinates and UT moments for all flashes of lightning detected by the network. The key features of the WWLLN system are presented in [Rodger et al., 2004] and on the website https://wwlln.net.

We have compiled global maps of lightning activity, which allow us to quantitatively estimate the global distribution of the total electric current in the GEC. These maps set up the initial state in the numerical model of the GEC.

\section{SPATIO-TEMPORAL ANALYSIS OF CLOUD-TO-GROUND LIGHTNINGS}

Figure 1 shows the intensity of lightnings in 20072009 (top panel) with the daily averaged solar activity index F10.7 (middle panel) and the geomagnetic activity index $A_{\mathrm{p}}$ (bottom panel). In Figure 1, the total number of flashes of lightning per day was divided by $86400 \mathrm{~s}$. The main visible feature is an increase in the lightning rate from 1.5 per second in 2007 to 4.5 per second at the end of 2009. This trend cannot be explained by solar or geomagnetic activity impact. 
Moreover, there were no solar flares and CMEs in 2009 , thus it was the year of the absolute minimum of solar activity. First, this can be explained by two major improvements in data processing in WWLLN, which were made in February 2008 and in April 2009. At the same time, we cannot neglect short-term meteorological variations in thunderstorm activity.

In [Blakeslee et al., 2014], the multiyear mean number of flashes of lightning was presented for optical data from OTD/LIS (Optical Transient Detector and the Lightning Imaging Sensor satellites). This instrumentation gives approximately 50 discharges per second, which is 20 times more than 2.6 discharges per second in WWLLN data during 2007-2009. This fact can be explained by instrumentation sensitivity and registration technique. A similar value has been obtained by Mezuman et al. [2014]; the authors have shown that the WWLLN system observes only $11 \%$ of cloud-to-ground discharges, though this value increases up to $30 \%$ for the discharges with large currents. The OTD/LIS system efficiently removes background optical radiation and can detect up to $90 \%$ of all flashes of all types (cloud-to-ground and intracloud). It is worthwhile to note that the satellite observes only the region $1300 \times 1300 \mathrm{~km}^{2}$. At the same time, the WWLLN system is truly global as far as it uses electromagnetic VLF sferics records in the processing algorithm. This algorithm skips all intracloud discharges. The decision rule requires that at least five stations must independently detect the same flash, thereby reducing the number of detected flashes of lightning. The related decrease in the number of flashes is another shortcoming of the WWLLN system. Nonetheless, this is negligible for the problem of long-term dynamics since it is reduced to a change in the vertical axis scale in Figure 1.

The global coverage by the WWLLN system removes the problem of the asynoptic nature of lightning detection by OTD/LIS. The asynoptic nature of satellite data is a well-known problem and it means the absence of observations at the same coordinates within the whole life-cycle of an orbital instrument. Salby [1982a, 1982b] has shown that direct interpolation and averaging of satellite data can lead to erroneous spatio-temporal fields. Thus, the finite frame of satellite data balances the lower sensitivity of WWLLN.

In Figure 2, we present the global annual maps for two systems [Kaplan, Lau, 2019; Cecil, 2015]. It is clear that the satellite system underestimates the number of flashes of lightning in Asia and the Pacific, as well as over oceans. At the same time, it overestimates the number of flashes of lightning over South America.

The correct input of spatio-temporal distribution of current sources to the GEC numerical model can be reduced to the analysis of the lightning coverage (see Section 4). It requires global coverage; thus Figure 2 allows us to consider WWLLN data as best suitable for the GEC problem.

As for comparison between distributions of lightnings in space and time, we compare our data with that collected in [Blakeslee et al., 2014], using scale 20 for the unified presentation in Figures.

\section{SEASONAL DEPENDENCE FOR THE GLOBAL NUMBER OF LIGHTNINGS}

Figures 3-6 present global maps for the density of lightnings for four seasons for the Northern Hemisphere. The number of lightnings per season was summed over the $5^{\circ} \times 5^{\circ}$ cells. Then it was divided by the area of the cells $\left[\mathrm{km}^{2}\right]$ and by the duration of the season under analysis [s]. The result in $1 /\left(\mathrm{s} \mathrm{km}^{2}\right)$ is referred to the center of a cell. The lightning location accuracy was $1 \mathrm{~km}$ and the time accuracy was $0.1 \mathrm{~s}$.
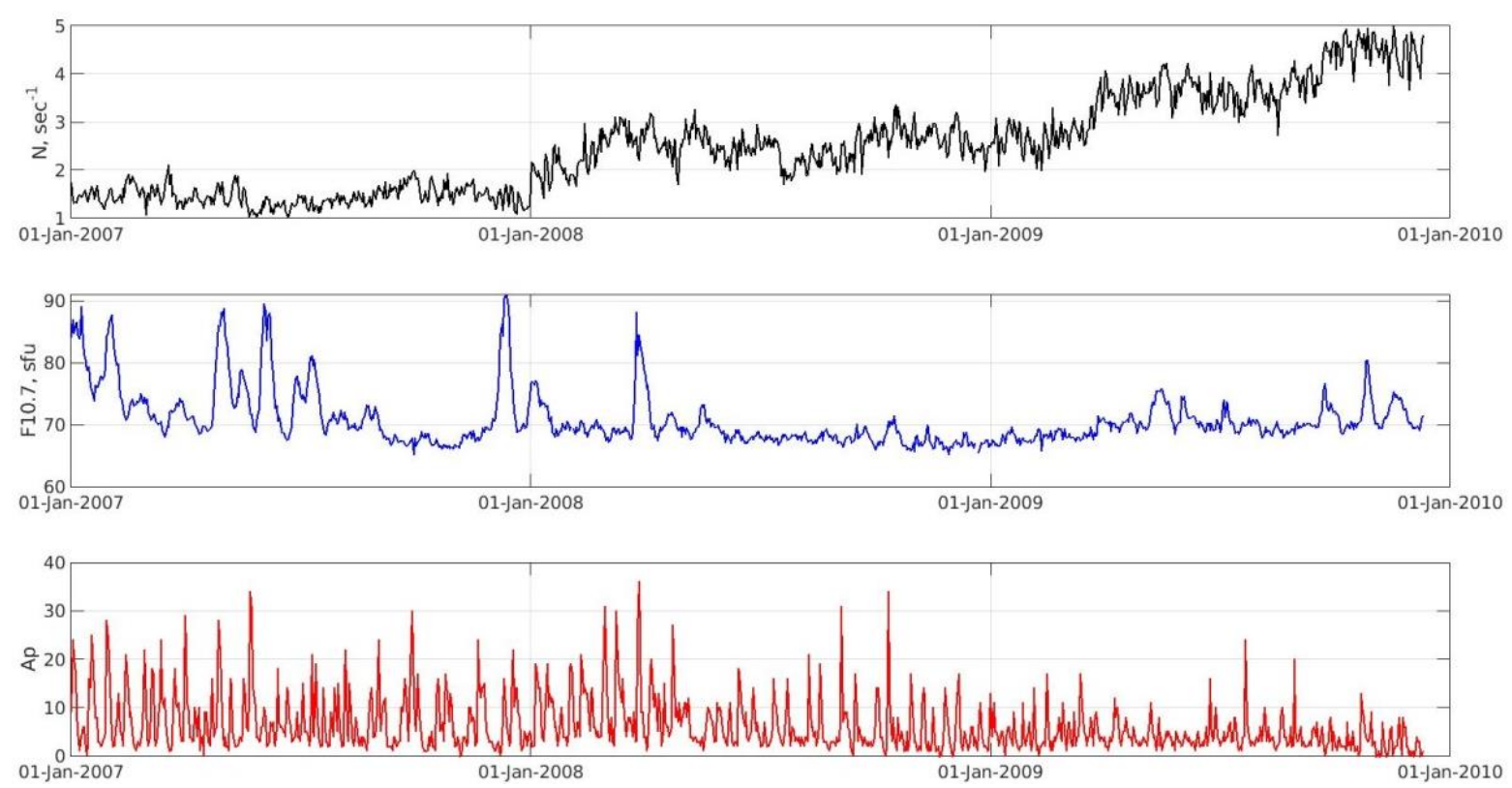

Figure 1. Global intensity of cloud-to-ground lightnings in 2007-2009 (top panel), the geomagnetic activity index $A_{\mathrm{p}}$ (middle panel), and solar activity index $F 10.7$ (bottom panel) 

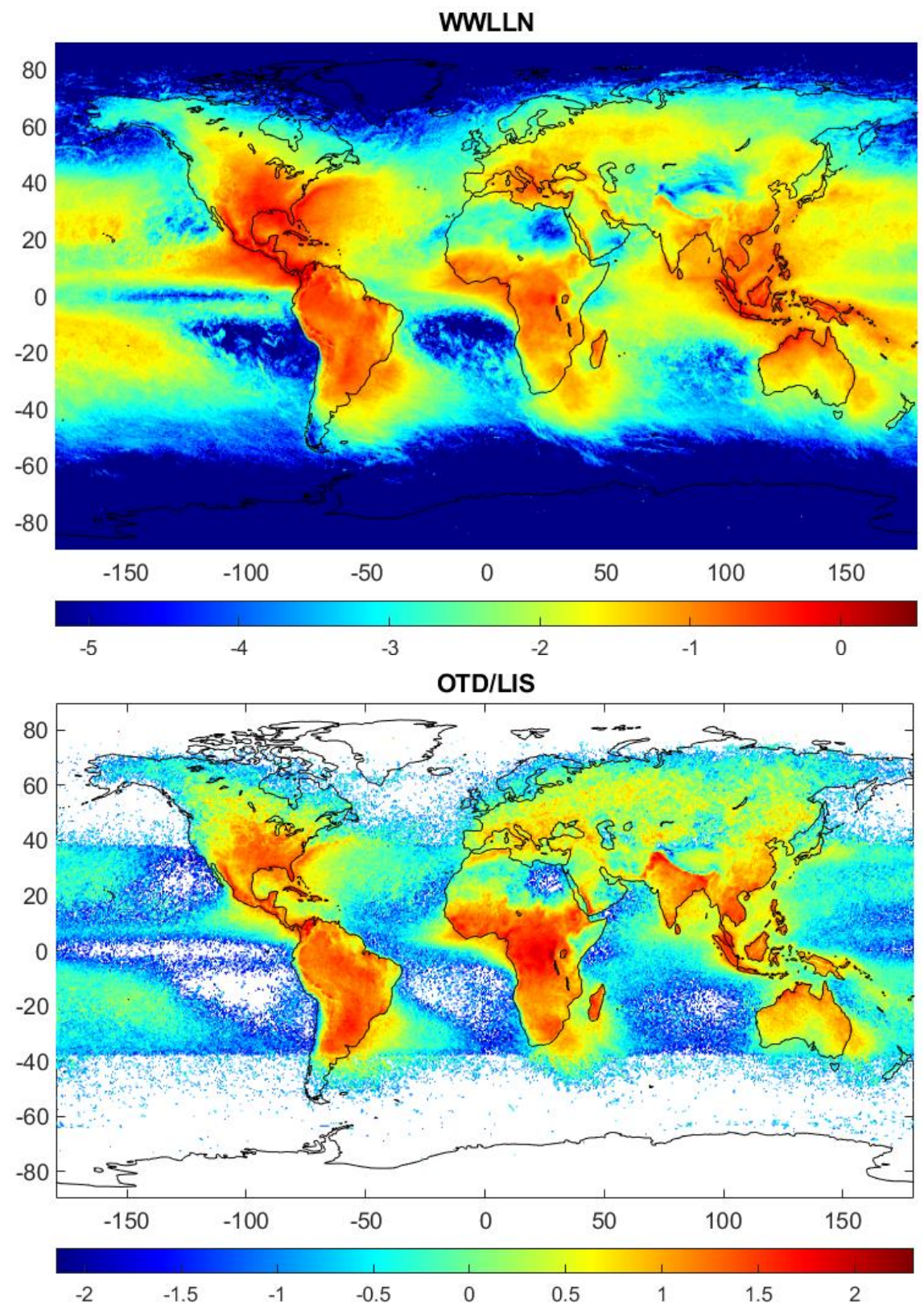

Figure 2. Annual mean number of lightnings from the ground-based WWLLN system $(a)$; annual mean number of lightnings from the OTD/LIS space-based system $(b)$. Logarithmic scale for the density in $\underset{-9}{1 /\left(\text { year } \mathrm{km}^{2}\right)}$ is used

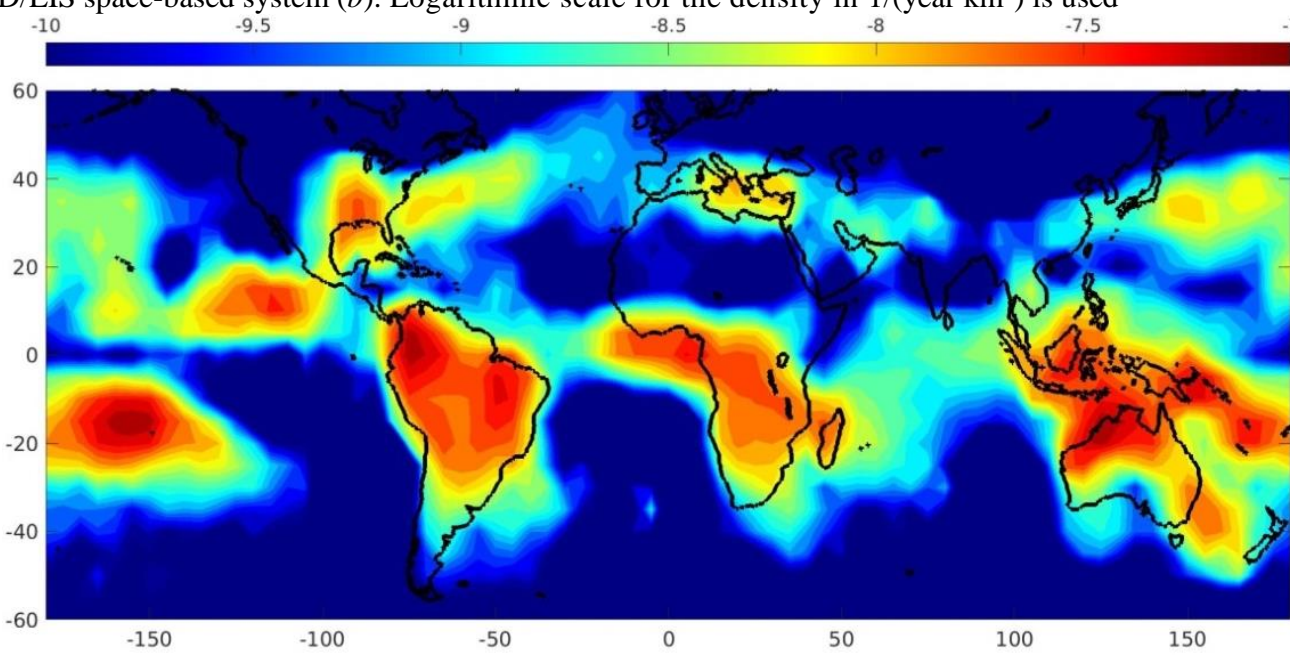

Figure 3. Global distribution of the lightning density in January and February 2009. Logarithmic scale for the density in $1 /\left(\mathrm{s} \mathrm{km}^{2}\right)$ is used 


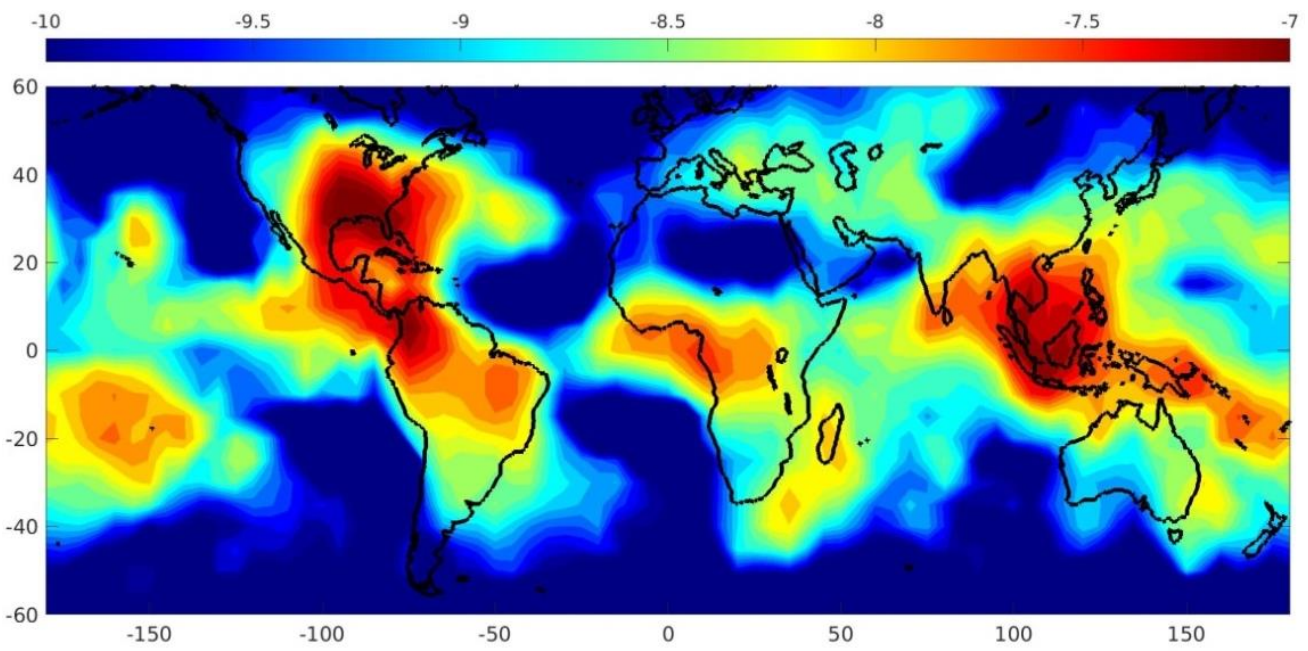

Figure 4. Global distribution of the lightning density in March to May 2009

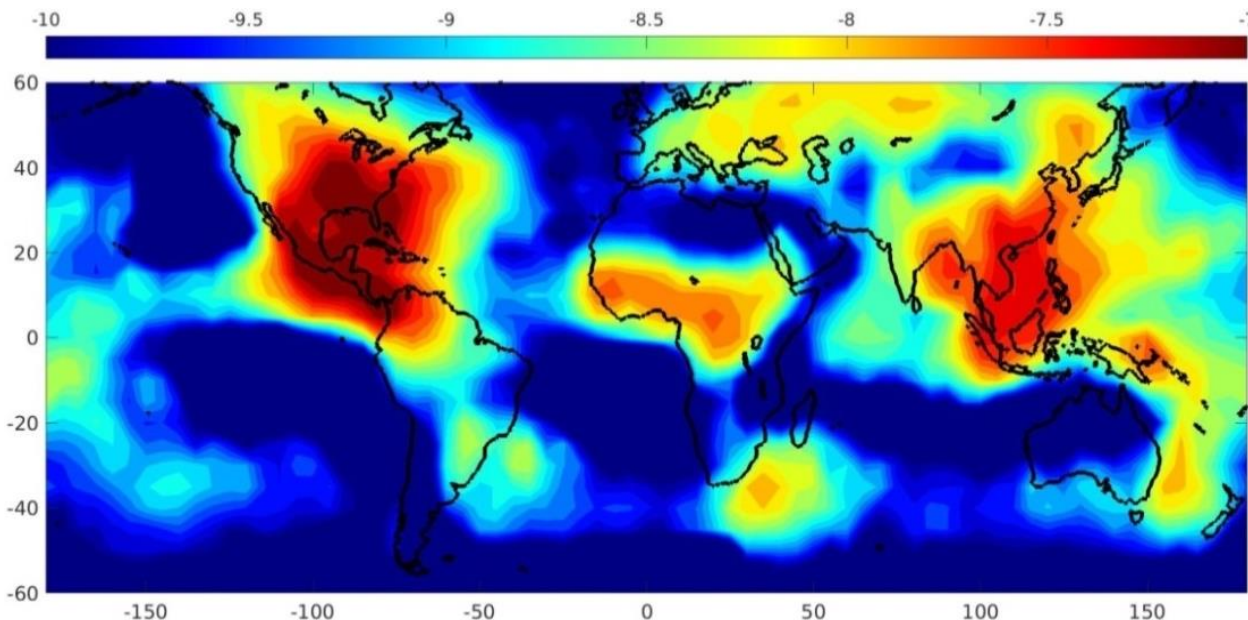

Figure 5. Global distribution of the lightning density in June to August 2009

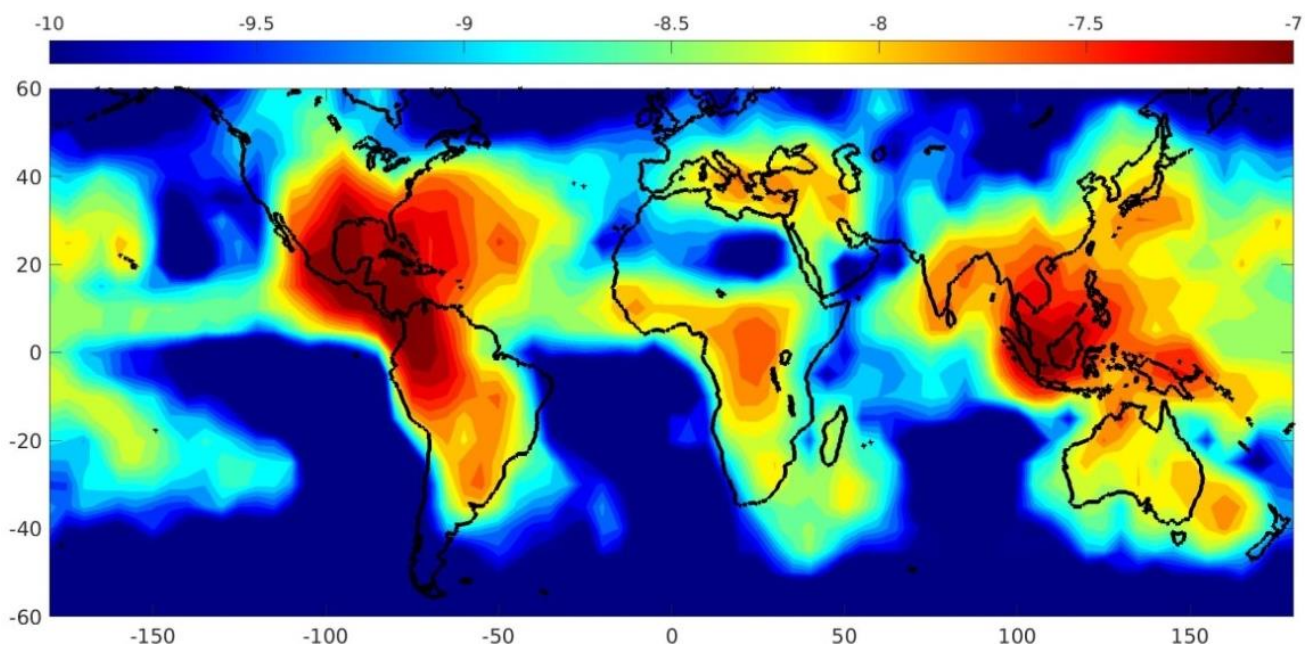

Figure 6. Global distribution of the lightning density in September to November 2009

Naturally, thunderstorm activity is higher at low latitudes and absent at high latitudes. According to the given color scale, lightnings do not exist poleward at latitudes above $60^{\circ}$; therefore, these regions are omitted.

Figure 7 illustrates the variation in the mean value for the latitude where lightnings are observed during the year (RMS is shown by error bars). The RMS bars in
Figure 7 have been calculated when considering the diurnal mean latitude as a random variable. If we consider coordinates of any certain lightning as a random process, the mean latitude value remains the same, whereas RMS increases by an order of magnitude. This is caused by a significant variation in latitude exceeding tens of degrees. Such a spread is seen in 
intensity maps (Figures 3-6). Recall that the distributions averaged over seasons are shown in these Figures.

Curves in Figure 7 are given for Earth as a whole and for three main thunderstorm centers. The latter are selected manually as sectors (America, Africa, and Asia, including oceans) divided by $140^{\circ} \mathrm{W}, 30^{\circ} \mathrm{W}$, and $60^{\circ} \mathrm{E}$. The shift of thunderstorm activity to the Northern Hemisphere is evident and statistically significant. The mean latitude is also shifted by $10^{\circ}$ from the annual mean to the summer hemisphere in all sectors.

\section{DAILY VARIATION OF LIGHTNING ACTIVITY}

The dependence of thunderstorm activity on the universal time (UT) is of special interest for the GEC theory as far as the dependence partially explains the Carnegie curve [Mach et al., 2011].

Figure 8 shows observable intensities (number of lightnings per second) with RMS for the three aforementioned sectors and for Earth as a whole as a function of UT. Raw data was hourly averaged in 2008 and referred to the half-hour. RMS values were calculated from the mean intensity for any given hour.
Thus, any certain point with RMS in Figures 8 and 10 was obtained from a set of 366 numbers, while in Figure 9 there are 92 numbers.

The lines without error bars are taken from [Blakeslee et al., 2014] with 20X scale. Since the number of lightnings in Europe is much less than in Africa, the difference between the African curves (our curve for the sector including Africa and Europe, and those taken from [Blakeslee et al., 2014]) should be negligible. Nevertheless, the difference is clear and proves that the discrepancy between satellite and ground-based data on lightning activity in Africa is significant. The results for 2007 and 2009 differ slightly. For Earth as a whole, the difference in the UT dependence is considerable as well as for the annual average thunderstorm activity (Figure 2).

The ground-based data has no significant (up to 1.5 times) increase, analogous to the Carnegie curve, at 1224 UT as compared to 00-12 UT [Harrison, 2013]. Despite the significant change in the number of lightnings $\left(1.5,2.6\right.$, and $3.8 \mathrm{~s}^{-1}$ in 2007, 2008, and 2009 respectively), the results for 2007 and 2009 also have no the aforementioned property. Diurnal variations occur

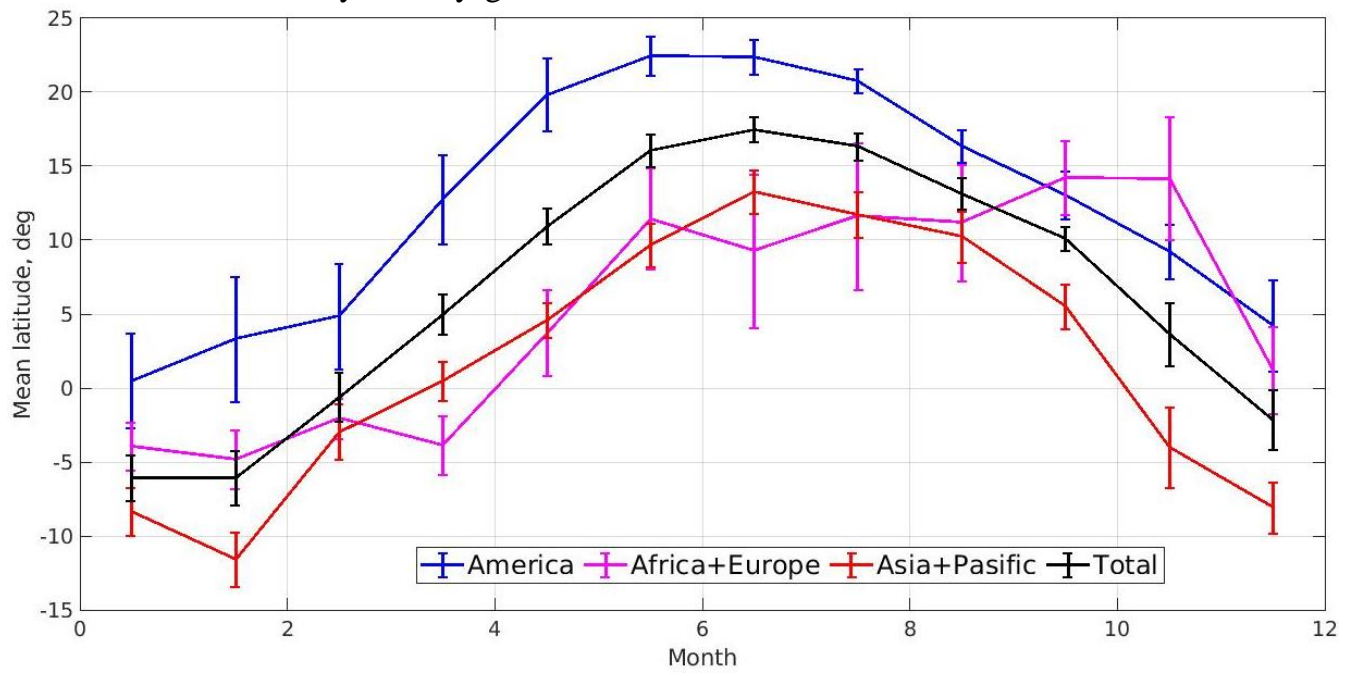

Figure 7. Monthly mean latitude of lightning observation in 2008

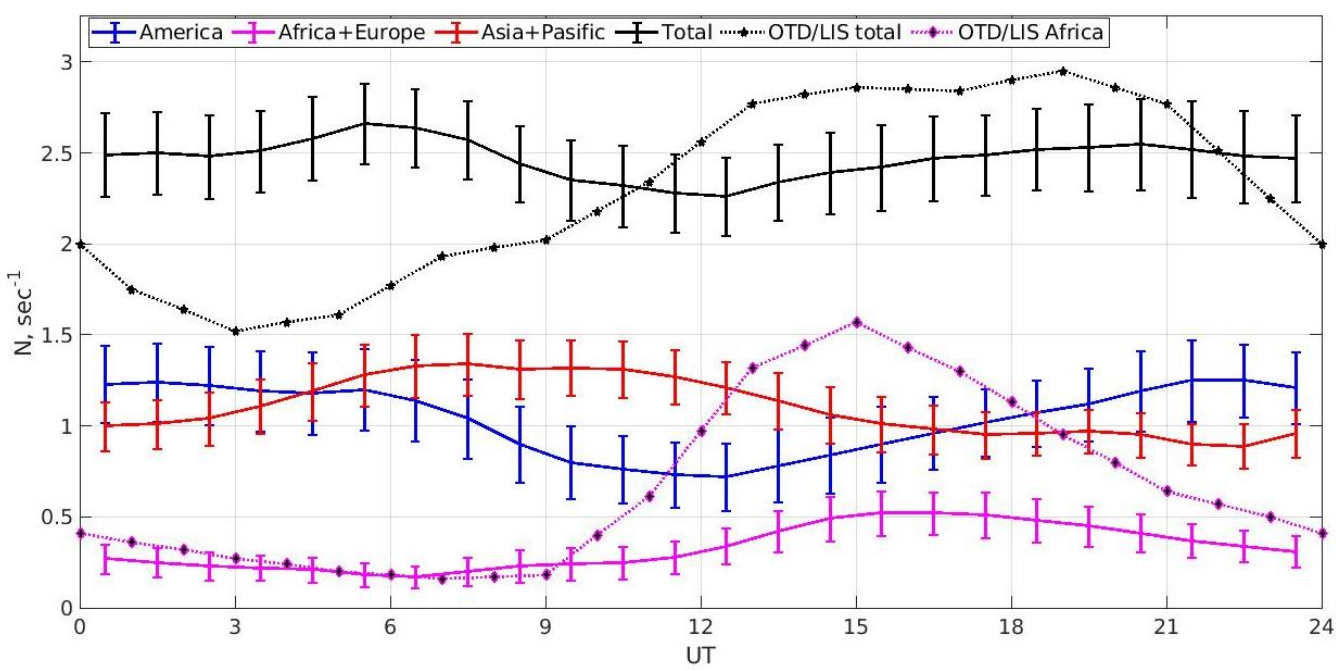

Figure 8. Daily average number of lightnings per second in 2008. OTD/LIS data is from [Blakeslee et al., 2014] downscaled 20 times 
due to other sectors. In Africa, the change in the number of lightnings was very weak in 2007-2009.

In other sectors, the diurnal variation derived from WWLLN is also weaker than from satellite data. In Asia and the Pacific, an increase was only 1.5 times instead of 4 ; in America, 1.8 times instead of 6 .

Figure 9 depicts the intensity of lightnings during the day separately for summer months. Comparing Figures 8 and 9 demonstrates that the difference between WWLLN and OTD/LIS data is not caused by annual averaging and is seen for each season.

Figure 10 presents the same data as in Figure 8 but as a function of the solar local time (LT). The local maximum for data from both WWLLN and OTD/LIS takes place at 15-18 LT. It is well known that 15-18 LT is the time of maximum heating of the surface and the troposphere. As in the case of UT, the maximum in WWLLN data is lower than in OTD/LIS data (Figure 10): The daily average number of lightnings per second for Earth as a whole is 2 times instead of 6; that for Africa, 2.5 times instead of 11 .
Figures 8 and 9 show the absence of correlation between the number of lightnings and the Carnegie curve. The same result was reported in [Mezuman et al., 2014] for the 7-year averaging over 2006-2012. In that work, the authors proposed to take the number of clusters instead of independent flashes. These clusters were defined as $1^{\circ} \times 1^{\circ}$ cells with more than 10 lightnings per hour. It was shown that the diurnal variation in the number of clusters is close to the Carnegie curve (the correlation coefficient is 0.95).

The aforementioned method was further elaborated in [Ccopa et al., 2021] for the analysis of 2012-2013 data. The diurnal variation in the number of clusters became closer to the Carnegie curve. For example, in the September-November period, the correlation coefficient increased up to 0.99 [Ccopa et al., 2021]. Such a high value may be attributed to the cluster definition as a combination of neighbor cells $\left(0.1^{\circ} \times 0.1^{\circ}\right)$ with more than one lightning per hour. It is necessary to proceed further with the study of lightning activity in and between solar cycles.

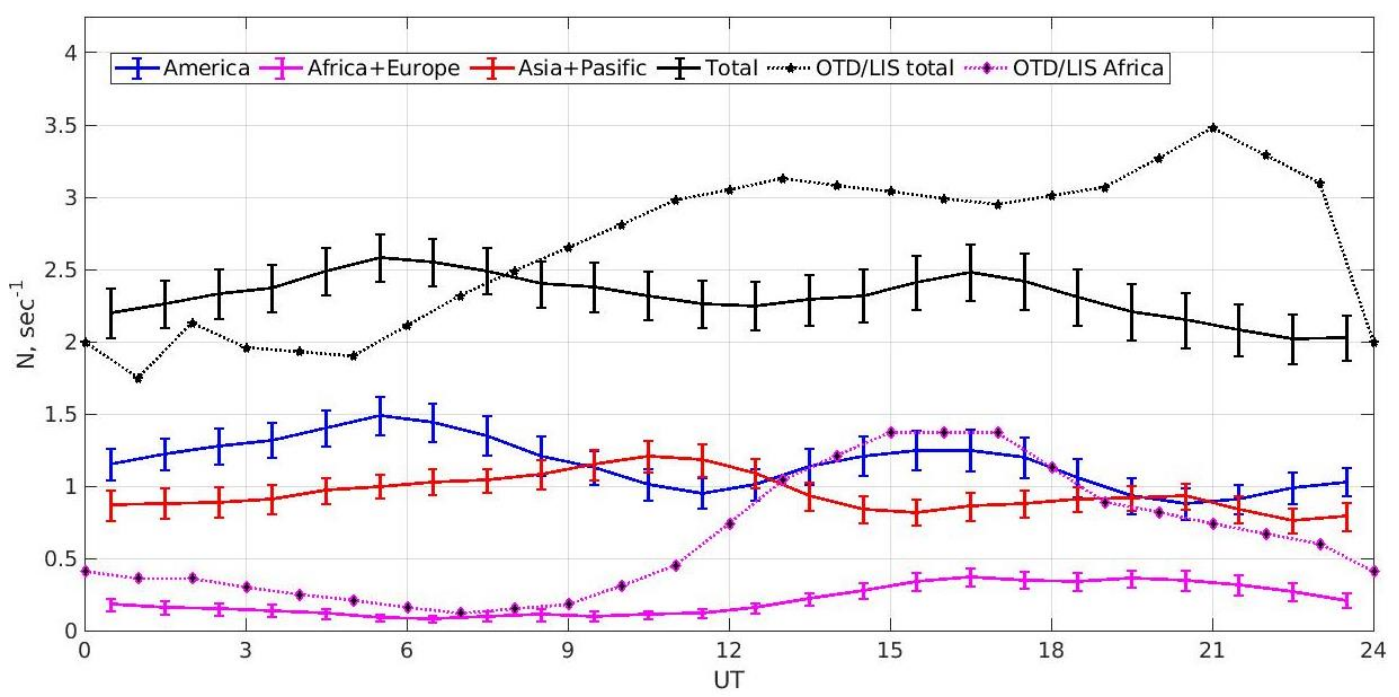

Figure 9. The same as in Figure 8 only for summer months

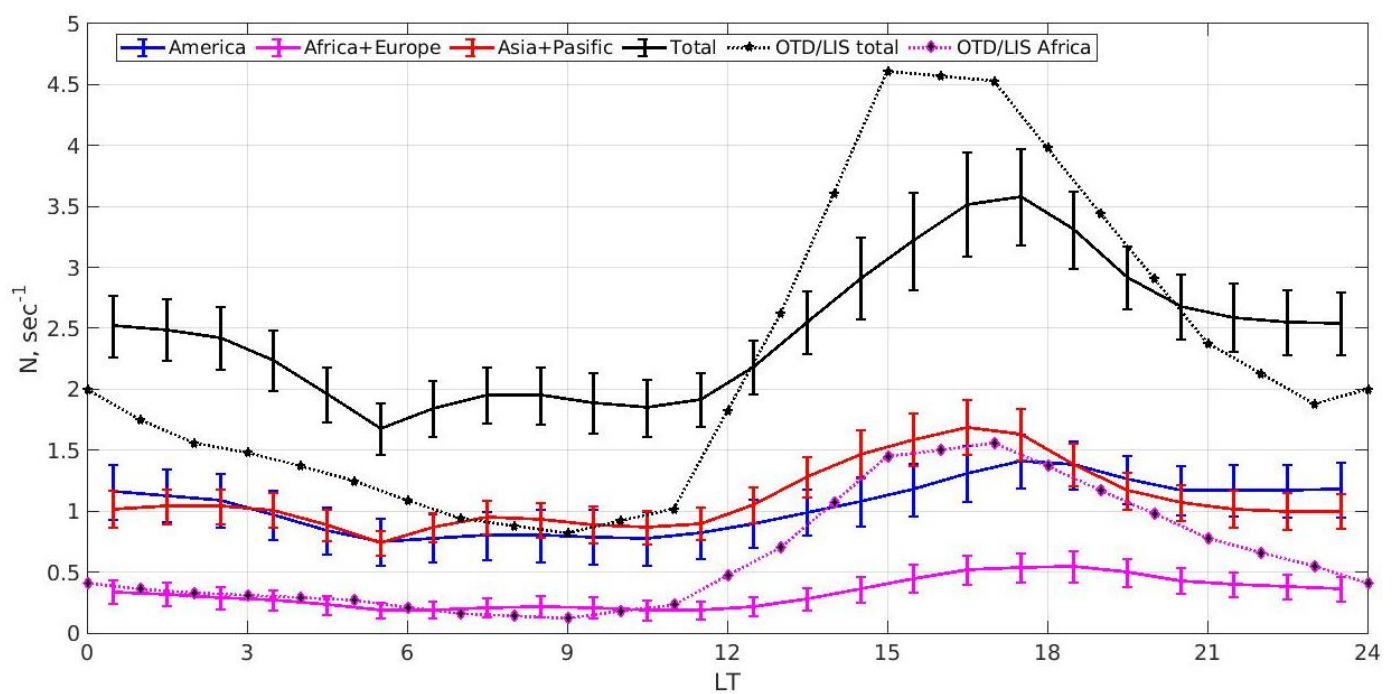

Figure 10. The same as in Figure 8 but with solar local time LT 


\section{USAGE OF THE CONSTRUCTED MAPS IN GEC MODELS}

The main generator in the GEC is all thunderstorms as a whole [Mareev, 2010]. Their cumulative parameter is the total conductive current to the ionosphere. Unfortunately, we have no instrument to measure this current; therefore, we have to use the procedure described below [Denisenko et al., 2019

First, we measure the electric field near the surface under fair weather conditions. This field $E_{0}$ is directed downward and has only $Z$ component due to large ground conductivity in comparison with atmosphere conductivity $\sigma(0)$. From the Ohm law we obtain the current density of vertical conductivity current near the surface $-j_{0}=-\sigma(0) E_{0}$. In the absence of charge sources in the atmosphere, the current density does not vary with altitude. This statement is true if we consider the stationary case, the spatial scale exceeds tens of kilometers, and we ignore Earth's curvature.

Next, using the measured atmosphere conductivity profile $\sigma(h)$ (up to $30 \mathrm{~km}$ altitude), we derive the electric field strength:

$$
E(h)=\frac{j_{0}}{\sigma(h)}=E_{0} \frac{\sigma(0)}{\sigma(h)} .
$$

Integrating the electric field between the surface and the ionosphere yields the potential difference:

$$
U_{0}=-\int_{0}^{H} E(h) d h=-E_{0} \int_{0}^{H} \frac{\sigma(0)}{\sigma(h)} d h .
$$

The upper integration limit $H$ is the altitude of the ionosphere and can be determined only approximately. It is of no importance because less than $1 \%$ of the integral is accumulated at a height above $30 \mathrm{~km}$ due to a rapid increase in $\sigma(\mathrm{h})$ with altitude (see Figure 5 in [Denisenko et al., 2019]).

From the voltage $U_{0}$ (it is also the potential of the ionosphere at the zero potential on the ground) and spatial distribution of the atmosphere conductivity, we derive the current density near Earth's surface:

$$
j(\lambda, \varphi)=\frac{U_{0}}{\Sigma(\lambda, \varphi)} .
$$

Here, $\lambda, \varphi$ are the longitude and latitude; and the conductivity of the $1 \mathrm{~m}^{2}$ column of air $\Sigma(\lambda, \varphi)$ can be found by integrating from the surface to the ionosphere

$$
\frac{1}{\Sigma(\lambda, \varphi)}=\int_{0}^{H} \frac{1}{\sigma(\lambda, \varphi, h)} d h .
$$

Finally, we integrate over Earth as a whole and obtain the total current from the ionosphere $I_{0}=U_{0} / R$, where the total resistance of the atmosphere $R$ can be calculated as

$$
\frac{1}{R}=\int \Sigma(\lambda, \varphi) R_{\mathrm{E}}^{2} \cos \lambda d \lambda d \varphi,
$$

where $R_{E}$ is the Earth radius.
The charge conservation under stationary conditions requires the same current from thunderstorms to the ionosphere $I_{0}=I$. The distribution of the thunderstorm current over Earth remains unknown. We assume that the current into the ionosphere and the number of lightnings are proportional to some hidden parameter that characterizes thunderstorm activity. Thus, we use the global distribution of lightning activity as a proxy for the thunderstorm current. Hence, the number of flashes of lightning and the total current are linearly dependent. In [Mach et al., 2011], coefficients are given for lightning discharges of various types, particularly for the ground and ocean. The smaller number of flashes of lightning in WWLLN data should change those coefficients, but we do not concern with the GEC model itself here. In the next section, we describe the possible transition from the number of lightnings to the number of clusters [Mezuman et al., 2014] and the choice of UT-dependent coefficients.

Non-thunderstorm clouds with well-developed electric structures (electrified clouds) can contribute to the current from the atmosphere to the ionosphere [Mareev, 2010]. According to [Blakeslee et al., 2014], their contribution amounts to $17 \%$. It is worthwhile to note that the significance of this contribution cannot be reconciled with the extremely high correlation between thunderstorm clusters and the Carnegie curve. The correlation coefficients obtained by [Ccopa et al., 2021], which reach 0.99 in autumn, leave no space for the electrified clouds or require the same UT-dependence for them as for thunderstorm clouds.

\section{COMPARISON WITH OTHER MODELS}

Figure 11 displays a global map of flashes of lightning in summer 2009 at 18-20 UT. The selection of two hours around 19:00 UT distinguishes Figure 11 from Figure 6 showing full days for all summer months. The famous paper [Hays and Roble, 1979] also presents a model of thunderstorm activity for 19:00 UT in July. It has been applied to the simulation of the ionospheric part of the GEC [Denisenko et al., 2019]. In our analysis, we use the aforementioned assumption of the linear dependence between the number of flashes of lightning and the electric current from the atmosphere to the ionosphere.

The electric current at 19:00 UT is about 45,15 , and $40 \%$ of the total current in the three aforementioned sectors respectively (see Figure 10). In the model by Hays and Roble [Hays and Roble, 1979], these ratios are 65,30 , and $5 \%$ respectively. Thus, the main difference is the tenfold underestimation of thunderstorms in Asia (5\% instead of $40 \%$ ). In sector 2, we combine Africa and Europe. But from Figure 11 it is clear that currents over Europe are not 30 times weaker than over Africa (20 A and $600 \mathrm{~A}$ in the model by Hays and Roble). Currents in other thunderstorm zones are close to our results. Thunderstorm regions have a complex shape with relatively weak currents in some locations.

An increase in the current to the ionosphere over Asia, which is under nocturnal conditions at 19:00 UT, 


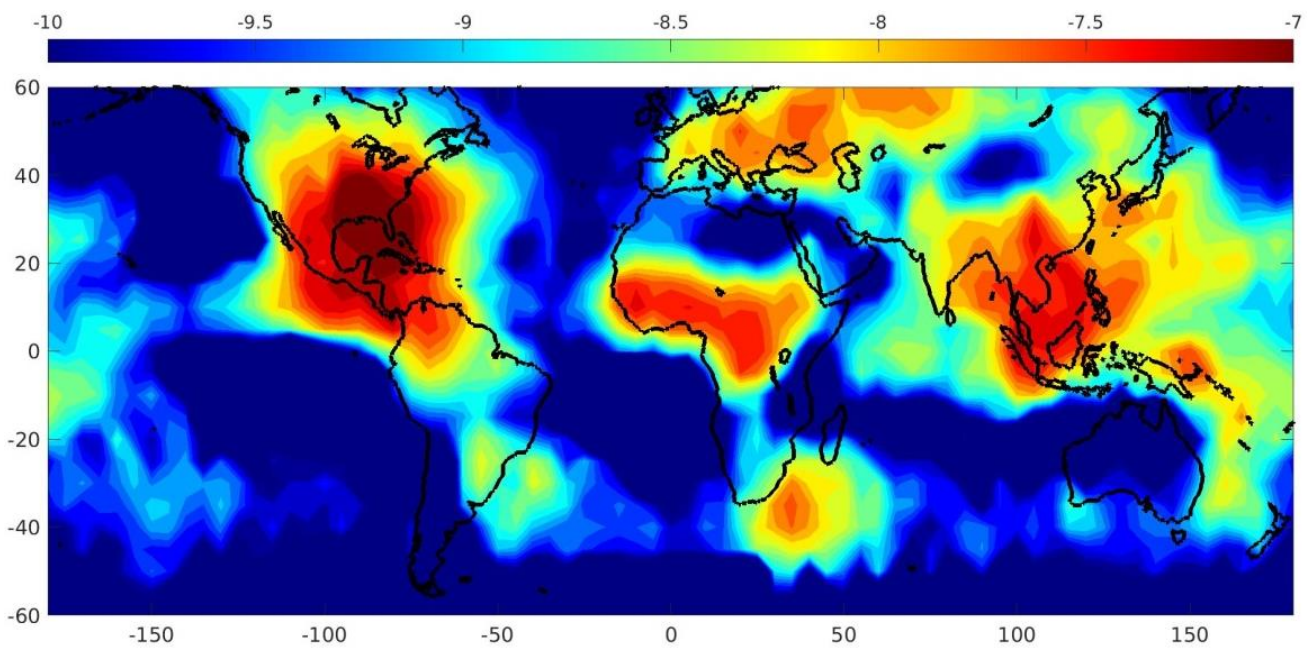

Figure 11. Global map of the lightning density in summer 2009, 18:00-20:00 UT

and over Europe, which is under terminator condition, leads to a significant increase in the potential difference inside the ionosphere.

The potential difference between the ground and the ionosphere does not depend on the geographical thunderstorm distribution. The key parameter is the total current into the ionosphere (see the previous section).

The global maps of lightning activity (Figures 3-6) qualitatively coincide with those from [Blakeslee et al., 2014] obtained from satellite data, including the summer shift to the Northern Hemisphere and the approximate location of major thunderstorm regions. This is valid for all seasons. There are significant differences too. The aforementioned three-fold difference in the total current in the African sector (Figure 9) exists under roughly the same spatial distributions (Figure 5). At the same time, for the Asian sector our Figure 5 shows the eastward shift of the lightning region in comparison with Figure 11 from [Blakeslee et al., 2014] (summer frame). Weaker currents are also observed over South America.

The relative smoothness of our distributions is explained as follows. Figure 11 in [Blakeslee et al., 2014] used $0.5^{\circ} \times 0.5^{\circ}$ averaging. In our Figure, we apply a coarser grid $5^{\circ} \times 5^{\circ}$ with further contouring by MATLAB tools. Our approach seems to be more adequate for large-scale structure visualization.

We have mentioned above that Figures 8 and 9 show no correlation between the number of lightnings from WWLLN and the Carnegie curve, whereas in [Mezuman et al., 2014, Ccopa et al., 2021] this correlation was found by transforming from separate lightnings to the number of clusters.

This proves that the cluster approach is useful for determining the number of thunderstorms. In turn, the thunderstorm current density from the atmosphere to the ionosphere can be derived from the number of thunderstorms. Note that there was no need to transform lightnings into clusters for OTD/LIS data [Blakeslee et al., 2014].

If we accept the Carnegie curve as the true test, our results can be normalized for the current density to the ionosphere, i.e. separate global distributions for various hours (see Figures 3-6) should be multiplied by different scale factors for each hour. Another question remains unanswered: Does the clusterization procedure [Mezuman et al., 2014, Ccopa et al., 2021] change the spatial properties of the distribution? The major thunderstorm regions in Figures 3-6 are consistent with the results from [Mezuman et al., 2014, Ccopa et al., 2021], as well as with the satellite data [Blakeslee et al., 2014]. This allows the constructed maps to be used in GEC simulation as an approximation for the thunderstorm current density from the atmosphere to the ionosphere.

\section{CONCLUSIONS}

We have presented global maps of lightning activity for 2007-2009. These maps are valuable for GEC numerical models. The total number of flashes of lightning in WWLLN data was shown to be smaller by an order of magnitude than in OTD/LIS data. The diurnal dependence similar to the Carnegie curve is absent in WWLLN data, but it exists in satellite data for Earth as a whole and for major thunderstorm regions. The local time dependence in WWLLN data is weak. The mean latitude of lightning observation was shifted to the summer hemisphere in 2007-2008. The total number of flashes of lightning in WWLLN data increased threefold from the beginning of 2007 to the end of 2009.

Further study should cover the last solar cycle and supplement WWLLN data with evidence on Schumann resonator parameters (frequency, amplitude, and quality factor). These parameters have been monitored at the Mikhnevo geophysical station of the Sadovsky Institute of Geosphere Dynamics since 2015 [Poklad et al., 2018, 2019].

For the WWLLN-based elaboration of spatial distribution for the thunderstorm current density to the ionosphere it would be appropriate to use the cluster technique proposed in [Mezuman et al., 2014, Ccopa et al., 2021]. 
The authors are grateful to the World Wide Lightning Location Network team (http://wwlln.net) for providing the lightning location data used in this paper.

This work is supported by the Krasnoyarsk Mathematical Center and financed by the Ministry of Science and Higher Education of the Russian Federation in the framework of the establishment and development of regional Centers for Mathematics Research and Education (Agreement No. 075-02-2021-1384).

The part of this work related with spatio-temporal analysis of the lightning activity is supported by state contract AAAA-A19-119028790056-6.

The authors express their gratitude to the anonymous reviewers for their valuable comments that have improved the article significantly.

\section{REFERENCES}

Analysis of Climate Variability. Eds H. von Storch, A. Navarra. Springer-Verlag, 1999, 342 p. DOI: 10.1007/978-3662-03744-7.

Blakeslee R.J., Mach D.M. Bateman M.G., Bailey J.C. Seasonal variations in the lightning diurnal cycle and implications for the global electric circuit. Atmosph. Res. 2014, vol. 135-136, pp. 228-243. DOI: 10.1016/j.atmosres.2012.09.023.

Cecil D.J. LIS/OTD Gridded Lightning Climatology Data Collection. 2015. Version 2.3.2015. HRFC_COM_FR. DOI: 10.5067/LIS/LIS-OTD/DATA311.

Ccopa J.G.A., Tacza J., Raulin J.-P., Morales C.A. Estimation of thunderstorms occurrence from lightning cluster recorded by WWLLN and its comparison with the 'universal' Carnegie curve. J. Atmos. Solar Terrs. Phys. 2021, vol. 221, 105682. DOI: $10.1016 /$ j.jastp.2021.105682.

Denisenko V.V., Rycroft M.J., Harrison R.G. Mathematical simulation of the ionospheric electric field as a part of the Global Electric Circuit. Surveys in Geophysics. 2019, vol. 40 (1), pp. 1-35. DOI: 10.1007/s10712-018-9499-6

Harrison R.G. The Carnegie Curve. Surveys in Geophysics. 2013, vol. 34, pp. 209-232. DOI: 10.1007/s10712-012-9210-2.

Hays P.B., Roble R.G. A quasi-static model of global atmospheric electricity. 1. The lower atmosphere. J. Geophys. Res. 1979, vol. 84 (A7), pp. 3291-3305. DOI: 10.1029/JA084iA12p07247.

Kaplan J.O., Lau H.-K.K. The WGLC global gridded monthly lightning stroke density and climatology. 2019. PANGAEA. DOI: 10.1594/PANGAEA.904253.

Mach D.M., Blakeslee R.J., Bateman M.G. Global electric circuit implications of combined aircraft storm electric current measurements and satellite-based diurnal lightning statistics. J. Geophys. Res. 2011, vol. 116, D05201. DOI 10.1029/2010JD014462.

Mareev E.A. 2010: Global electric circuit research: achievements and prospects, UFN, 180:5 (2010), 527-534; Phys. Uspekhi. 2010, 53:5, pp. 504-511. DOI: 10.3367/UFNr.0180.201005h.0527.

Mezuman K., Price C., Galanti E. On the spatial and temporal distribution of global thunderstorm cells. Environ. Res. Lett. 2014. vol. 9 (12), 124023. DOI: 10.1088/17489326/9/12/124023.

Poklad Y.V., Ermak V.M., Ryakhovskiy I.A. Influence of local time and power of solar $\mathrm{X}$-ray flashes of $\mathrm{M}$ and $\mathrm{X}$ classes on the variation of frequency of first mode of Schumann resonance. 24th International Symposium on Atmospheric and Ocean Optics: Atmospheric Physics. International Society for Optics and Photonics, SPIE. 2018. vol. 10833, pp. 2091-2094. DOI: 10.1117/12.2504511.
Poklad Y.V., Ermak V.M., Ryakhovskiy I.A., Rybakov V. Variation of frequency of first modeof schumann resonance under solar X-ray flashes and its relation with heliogeophysical conditions. 25th International Symposium on Atmospheric and Ocean Optics: Atmospheric Physics. International Society for Optics and Photonics, SPIE. 2019, vol. 11208, pp. 1910-1913. DOI: 10.1117/12.2540671.

Rodger C.J., Brundell J.B., Dowden R.L., Thomson N.R. Location accuracy of long distance VLF lightning location network. Ann. Geophys. 2004, vol. 22, pp. 747-758. DOI: 10.5194/angeo-22-747-2004.

Rycroft M.J., Israelsson S., Price C. The global atmospheric electric circuit, solar activity and climate change. J. Atmos. Solar-Terr. Phys. 2000, vol. 62, pp. 1563-1576. DOI: 10.1016/S1364-6826(00)00112-7.

Salby M.L. Sampling theory for asynoptic satellite observations Part I: Space-time spectra, resolution and aliasing. J. Atmos. Sci. 1982a, vol. 39, pp. 2577-2600. DOI: 10.1175/1520-0469(1982)039<2577:STFASO>2.0.CO;2.

Salby M.L. Sampling theory for asynoptic satellite observations. Part II: Fast Fourier synoptic mapping. J. Atmos. Sci. 1982b, vol. 39 (11), pp. 2601-2614. DOI: $10.1175 / 1520$ 0469(1982)039<2601:STFASO>2.0.CO;2.

Tinsley B.A. Influence of the solar wind on the global electric circuit, and inferred effects on cloud microphysics, temperature, and dynamics of the troposphere. Space Sci. Rev. 2000, vol. 94, pp. 231-258. DOI: 10.1023/A:1026775408875.

Williams E.R. Lightning and climate: A review. Atmos. Res. 2005, vol. 76, pp. 272-287. DOI: 10.1016/j.atmosres.2004.11.014.

URL: https://wwlln.net (accessed October 20, 2021).

How to cite this article

V.V. Denisenko, A.N. Lyakhov. Comparison of ground-based and satellite data on spatiotemporal distribution of lightning discharges under solar minimum. Solar-Terrestrial Physics. 2021. Vol. 7. Iss. 4. P. 104-112. DOI: $10.12737 /$ stp-74202112. 